\title{
Isolamento e PCR para detecção de Mollicutes em muco vaginal e sua associação com problemas reprodutivos em ovinos criados na região de Piedade, São Paulo, Brasil
}

\author{
Mollicutes isolation and PCR on ovine vaginal mucous and its association with reproductive \\ problems in Piedade, SP, Brazil
}

\author{
Huber Rizzo ${ }^{\mathrm{I}}$ Enoch Brandão de Sousa Meira Junior ${ }^{\mathrm{I}}$ Rosângela Claret de Oliveira ${ }^{\mathrm{II}}$ \\ Maurício Yamaguti ${ }^{\mathrm{II}}$ Melissa Buzinhani ${ }^{\mathrm{II}}$ Jorge Timenetsky $^{\mathrm{II}}$ Lilian Gregory $^{\mathrm{I}^{*}}$
}

\begin{abstract}
RESUMO
Pesquisou-se Mycoplasma spp, Ureaplasma spp e Acholeplasma laidlawiii em amostras de muco vaginal de 60 ovinos, criados na região de Piedade no Estado de São Paulo, Brasil, que apresentavam ou não vulvovaginite no exame específico do sistema genital. A caracterização desses microrganismos baseou-se no cultivo e detecção do respectivo DNA pela Reação da Polimerase em Cadeia (PCR) com os primers para classe Mollicutes (GPO e MGSO), para o gênero Ureaplasma (UGPF e UGPS) e a espécie Acholeplasma laidlawii (UNI e ACH3). A presença de micoplasmas não foi associada com distúrbios do trato reprodutivo dos animais, entretanto todos os isolados obtidos de Ureaplasma spp foram provenientes de animais com distúrbios reprodutivos, sugerindo o possível envolvimento desse agente nas enfermidades da reprodução. A PCR para a espécie Acholeplasma laidlawii detectou somente uma amostra positiva.
\end{abstract}

Palavras-chave: $P C R$, micoplasmas, ureaplasma, ovelhas, vulvovaginite.

\section{ABSTRACT}

It was evaluated the presence of Mycoplasma spp, Ureaplasma spp and Acholeplasma laidlawiii in 60 samples of ovine vaginal mucous with the presence or absence of vulvovaginitis in the specific exam of the reproductive tract. The microorganisms were characterized based on bacteriological culture and DNA detection by Polymerase Chain Reaction (PCR) with specific primers to Mollicutes (GPO and $M G S O$ ), Ureaplasma (UGPF and UGPS) and Acholeplasma laidlawii (UNI and ACH3). The presence of mycoplasmas could not be associated with reproductive disorders in animals. The PCR to Acholeplasma laidlawii detected only one positive sample. However, all isolations of Ureaplasma spp were from animals presenting reproductive disorders, suggesting a possible involvement of this agent in reproductive diseases.

Key words: PCR, mycoplasmas, ureaplasmas, sheep, vulvovaginitis.

\section{INTRODUÇÃO}

A família Mycoplasmatacea, pertencente à classe Mollicutes, é composta por 14 gêneros, sendo os de interesse veterinário Mycoplasma, Ureaplasma e Acheloplasma (BERGEY'S, 2001). Considerados os menores microrganismos de vida livre capazes de autoreplicação (RAZIN, 2006), essas bactérias têm predileção por membranas serosas ou mucosas (CLAYDE, 1983). As infecções por micoplasmas em ovinos podem apresentar-se de forma aguda, porém as manifestações crônicas são mais frequentes. Essas infecções podem resultar em distúrbios reprodutivos em pequenos ruminantes causando vulvites, vaginites, cervicites e endometrites (RANA et al., 1993) com consequentes perdas econômicas na ovinocultura brasileira. Na espécie bovina, o Ureaplasma diversum é um dos agentes causadores da vulvovaginete granular já relatada em rebanhos brasileiros (CARDOSO et al., 2000), assim como o $\boldsymbol{M}$. bovigenitalium e $\boldsymbol{M}$. canadenses responsáveis por surtos de vulvovaginite granulopapular (LYSNYANSKY et al., 2009).

'Departamento de Clínica Médica, Faculdade de Medicina Veterinária e Zootecnia, Universidade de São Paulo (USP), 05508-270,

São Paulo, SP, Brasil. Email: lgregory@usp.br. *Autor para correspondência

IIDepartamento de Microbiologia, Instituto de Ciências Biomédicas, USP, São Paulo, SP, Brasil. 
$\mathrm{O}$ primeiro relato de micoplasmose em ovinos foi realizado na Austrália (COTTEW et al., 1974). Mycoplasma (M.) ovine/caprine sorotipo 11, ainda não classificado como espécie, conhecido como cepa 2D foi relacionado a casos de vulvovaginite e problemas reprodutivos em ovinos e caprinos na Austrália, Estados Unidos, Índia, Inglaterra, França e Nigéria (NICHOLAS et al., 1999). Inoculações experimentais da cepa acima citada causaram quadro de vulvovaginite granular (VVG), caracterizada por edema de vulva, descargas uterinas, vulvitis, vaginite, cervicite e endometrite (KUMAR et al., 1992). Outras espécies foram isoladas do trato reprodutivo com poder patogênico, são elas: $\boldsymbol{M}$. mycoides subsp. mycoides, M. bovigenitalium, M. agalactiae, M. mycoides subps. capri, M. capricolum, M. arginini, M. alkalencens eAcholeplasma spp. (JONES et al., 1983; KAPOOR et al., 1984). Em rebanhos infectados por ureaplasmas, verificou-se diminuição na taxa de natalidade, aumento em morte neonatal e repetição de cio (BALL et al., 1984). LIVINGSTON JUNIOR \& GAUER (1983) consideraram a possibilidade de os ureaplasmas estarem associados às perdas reprodutivas devido a falhas na concepção, na implantação do embrião no útero ou interferência no desenvolvimento fetal. A infecção por ureaplasmas pode resultar em placentite, mas o abortamento não indica necessariamente a ocorrência de surto por esse agente (PUGH, 2005). No Brasil, existem poucos estudos que avaliam o envolvimento dos Mollicutes às alterações reprodutivas nas espécies ovinas e caprinas e esse tema ainda deve ser mais explorado. GREGORY et al. (2004) descreveram o primeiro relato de isolamento desse agente obtido de sêmen e muco vaginal de ovelhas provenientes do Estado de São Paulo. Este estudo teve por objetivo avaliar a presença das micoplasmoses em pequenos ruminantes e seu impacto na reprodução.

\section{MATERIAL E MÉTODOS}

Foram colhidas as amostras durante todo o ano de sessenta ovelhas mestiças, adultas, de aproximadamente $60 \mathrm{~kg}$, pertencentes a seis rebanhos situados no município de Piedade no estado de São Paulo (LA -234' $43^{\prime \prime}$, LO $47^{\circ} 25^{\prime} 40^{\prime}$ ) e onde foram utilizados dos rebanhos A, B, C, D, E e F, respectivamente, 19, 17, 11, 5, 5, e 3 ovelhas. Estas foram avaliadas pelo exame ginecológico, sendo 20 sadias e 40 apresentando vulvovaginite, e submetidas à colheita de muco vaginal por meio da fricção de zaragatoa na mucosa. O muco vaginal foi transportado em 3mL de meios específicos, SP4 para micoplasma e
UB para ureaplasma, sob refrigeração. O processamento das amostras foi realizado em período inferior a 24 horas após colheita. Cinquenta microlitros de cada meio de transporte, contendo a amostra, foram inoculados em $1,8 \mathrm{~mL}$ de meio (UB e SP4), homogeneizados e realizadas três diluições decimais de cada amostra. Da última diluição $\left(10^{-4}\right)$, foram retirados $50 \mu \mathrm{L}$ e semeados em meio sólido (1\% de ágar) SP4 e UB. As culturas foram incubadas por 15 dias a $37^{\circ} \mathrm{C} \mathrm{em}$ aerobiose para o meio UB e microaerofilia para o meio SP4. O crescimento foi caracterizado inicialmente pela produção de colônias em forma de "ovo frito" e pela utilização da glicose e/ ou arginina, resultando, respectivamente, em acidez ou alcalinização dos meios líquidos (RAZIN \& TULLY, 1983). Os ureaplasmas foram caracterizados pela hidrólise da uréia, que resulta em alcalinização do meio UB, produção de colônias de coloração marrom, devido à precipitação de cátions de manganês, e pela aparência granulosa (RUHNKE \& ROSENDAL, 1994). Para a obtenção do DNA, destinado a PCR, foram utilizados $20 \mathrm{~mL}$ de cultura de cada cepa de referência de Ureaplasma (U.) diversum ATCC sorogrupo A (49782), A. laidlawaii (PG-8), M. arginini (G-230), M. bovis (Donetta) e um mililitro do material clínico, submetidos à extração pelo método da fervura descrito por FAN et al. (1995). APCR foi realizada com os primers para classe Mollicutes (GPO e MGSO) (VAN KUPPEVELD et al., 1993), para o gênero Ureaplasma (UGPF e UGPS) (LAUERMAN, 1998) e a espécie $\boldsymbol{A}$. laidlawii (UNI e ACH3) (DUSSURGETT \& DUSSOIX, 1994), localizados na região interna do gene $16 \mathrm{~S}$ do rRNA. (Tabela 1). Para a reação em cadeia da polimerase dos Mollicutes foi adicionado a um microtubo $(0,2 \mathrm{~mL}) 50 \mathrm{pmol}$ de cada primer, $2 \mathrm{U}$ de Taq DNA polimerase, $2,0 \mathrm{mM}$ de $\mathrm{MgCl}_{2}$, $100 \mu \mathrm{M}$ de deoxiribonucleotídeos trifosfato (dNTP), $5 \mu \mathrm{L}$ da amostra de DNA e água ultrapura até o volume final de $50 \mu \mathrm{L}$. A amplificação foi realizada em termociclador (PCR Express Thermal Cycler-Thermo Hybaid), programado para um ciclo de $94^{\circ} \mathrm{C}$ durante cinco min, 35 ciclos de $94^{\circ} \mathrm{C}$ durante $30 \mathrm{~s}, 55^{\circ} \mathrm{C}$ durante $30 \mathrm{~s}, 72^{\circ} \mathrm{C}$ durante $30 \mathrm{~s} \mathrm{e} \mathrm{um} \mathrm{ciclo} \mathrm{final} \mathrm{de} 72^{\circ} \mathrm{C}$ por 10 min. Para a reação em cadeia da polimerase do gênero Ureaplasma spp., foi adicionado a um microtubo (0,2mL) 20pmol de cada primer, 1,25U de Taq DNA polimerase, $2,0 \mathrm{mM}$ de $\mathrm{MgCl}_{2}, 50 \mu \mathrm{M}$ de deoxiribonucleotídeos trifosfato (dNTP), $5 \mu \mathrm{L}$ da amostra de DNA e água ultrapura até o volume final de $50 \mu \mathrm{L}$. A amplificação foi realizada em termociclador programado para: 40 ciclos a $94^{\circ} \mathrm{C}$ durante $30 \mathrm{~s}, 55^{\circ} \mathrm{C}$ durante $30 \mathrm{~s}, 72^{\circ} \mathrm{C}$ durante $60 \mathrm{~s}$ e um ciclo final de $72^{\circ} \mathrm{C}$ por cinco min. Para a reação em cadeia da polimerase de $\boldsymbol{A}$. laidlawii, foi adicionado a um microtubo $(0,2 \mathrm{~mL})$ 
Tabela 1 - Primers para classe Mollicutes (GPO e MGSO), para o gênero Ureaplasma (UGPF e UGPS) e a espécie A. laidlawii (UNI e $\mathrm{ACH} 3)$, localizados na região interna do gene 16S do rRNA utilizados para a realização do PCR das amostras de swab vaginal de fêmeas ovinas. Piedade - São Paulo, 2005.

\begin{tabular}{|c|c|c|c|}
\hline Primers & Sequência & Produto & Autor \\
\hline \multicolumn{4}{|l|}{ Mollicutes } \\
\hline GPO3 & 5'- GGG AGC AAA CAG GAT TAG ATAC CCT-3' & \multirow{2}{*}{$270 \mathrm{pb}$} & \multirow{2}{*}{ Van KUPPEVELD et al., 1993} \\
\hline MGSO & 5'- TGC ACC ATC TGT CAC TCT GTT AAC CTC-3' & & \\
\hline \multicolumn{4}{|c|}{ Ureaplasma } \\
\hline UGPF & 5'-GGATGAGGGTGCGACGTATC-3' & \multirow{2}{*}{$644 \mathrm{pb}$} & \multirow{2}{*}{ LAUERMAN, 1998} \\
\hline UGPR & 5'-GCGTTAGCTACAACACCGAC -3' & & \\
\hline \multicolumn{4}{|c|}{ A. laidlawii } \\
\hline UNI & 5'- TAATCCTGTTTGCTCCCCAC-3' & \multirow{2}{*}{$505 \mathrm{pb}$} & \multirow{2}{*}{ DUSSURGETT \& DUSSOIX, 1994} \\
\hline $\mathrm{ACH} 3$ & 5'-AGCCGGACTGAGAGGTCTAC-3' & & \\
\hline
\end{tabular}

40pmol de cada primer, $1 \mathrm{U}$ de Taq DNA polimerase, $1,2 \mathrm{mM}$ de $\mathrm{MgCl}_{2}, 200 \mu \mathrm{M}$ de deoxiribonucleotídeos trifosfato (dNTP), $1 \mu \mathrm{L}$ da amostra de DNA e água ultrapura até o volume final de $50 \mu \mathrm{L}$. A amplificação foi realizada em termociclador programado para: um ciclo de $95^{\circ} \mathrm{C}$ por $5 \mathrm{~min}, 30$ ciclos de $95^{\circ} \mathrm{C}$ por $30 \mathrm{~s}, 64^{\circ} \mathrm{C}$ por $1,5 \mathrm{~min}, 72^{\circ} \mathrm{C}$ por $1,5 \mathrm{~min}$ e um ciclo final de $72^{\circ} \mathrm{C}$ por $10 \mathrm{~min}$. Os produtos da PCR $(10 \mu \mathrm{L})$ foram separados por eletroforese em gel de agarose a 1,5\%, contendo $10 \mu \mathrm{g} \mathrm{mL}^{-1}$ de brometo de etídio em tampão TAE (40mM Tris-acetato; 2mM EDTA, pH 8,0). A visualização e fotodocumentação dos produtos foram realizadas sob luz ultravioleta. O marcador de peso molecular utilizado foi 100pb DNA Ladder (Invitrogen).

\section{RESULTADOS}

Foi realizado o exame microbiológico de 60 amostras de muco vaginal em meio SP4 e, destas, 42 sofreram contaminação por bactérias ambientais e foram descartadas. As 18 amostras não contaminadas resultaram em seis (33\%) isolamentos. No cultivo das 60 amostras cultivadas em meio UB, 22 não apresentaram contaminação, resultando em sete $(31,8 \%)$ isolados (Tabela 2). Os isolados de Mollicutes eram provenientes de amostras de animais que possuíam ou não no momento do exame ginecológico vulvovaginite, enquanto os isolados de Ureaplasma spp provinham de ovinos com histórico de distúrbios reprodutivos.
Foi realizada a triagem das 60 amostras de muco vulvovaginal com o PCR da classe Mollicutes que resultaram em $45(75 \%)$ reações positivas. Quando as amostras foram submetidas a PCR gênero Ureaplasma, o resultado foi de 40 reações positivas $(66,7 \%)$. A PCR espécie A. laidlawii detectou apenas uma amostra positiva $(1,7 \%)$. Dentre as amostras positivas para Mollicutes, 88,9\% (40/45) foram positivas para o gênero Ureaplasma. Os resultados obtidos pela associação de presença ou ausência de vulvovaginite com os resultados das PCRs (Mollicutes e Ureaplasma) encontram-se na tabela 3 .

\section{DISCUSSÃO}

A associação dos molicutes aos problemas reprodutivos em ovinos é pouco pesquisada no Brasil e em outros países. O diagnóstico ineficaz pode ser decorrente do desconhecimento dessas enfermidades por técnicos e médicos veterinários, além da ausência de laboratórios especializados (BUZINHANI et al., 2007). No Brasil, há relatos de isolamentos de $\boldsymbol{M}$. conjuntivae de ceratoconjuntivite caprina (GREGORY et al., 2003) e ovina (ALMEIDA NETO et al., 2004), Ureaplasma spp em muco vulvovaginal/sêmen de ovinos e caprinos (GREGORY et al., 2004) e $\boldsymbol{M}$. agalactiae em leite e líquido sinovial de cabras apresentando artrite e mastite (AZEVEDO et al., 2006). No entanto, as dificuldades no isolamento, devido às

Tabela 2 - Frequência e percentual de isolamento de Mycoplasma spp em meio SP4 e Ureaplasma spp em meio UB de culturas não contaminadas e contaminadas, obtidos de amostras de muco vulvovaginal de ovinos criados na região de Piedade - São Paulo, 2005.

\begin{tabular}{lcc}
\hline Espécies & Isolamentos de amostras não contaminadas & Isolamentos do total de amostras \\
\hline Mycoplasma spp & $06 / 18(33,0 \%)$ & $6 / 60(10 \%)$ \\
Ureaplasma spp & $07 / 22(31,8 \%)$ & $7 / 60(11,7 \%)$ \\
\hline
\end{tabular}


Tabela 3 - Presença e ausência de vulvovaginite segundo PCR classe Mollicutes e gênero Ureaplasma spp em ovinos criados na região de Piedade - São Paulo, 2005.

\begin{tabular}{lccccc}
\hline & & Presença de vulvovaginite & Ausência de vulvovaginite & Total & $\mathrm{p}$ \\
\hline Mollicutes & $(+)$ & 31 & 14 & 45 & \\
Mollicutes & $(-)$ & 09 & 06 & 45 & 0.752 \\
Ureaplasma spp & $(+)$ & 29 & 11 & 40 & \\
Ureaplasma spp & $(-)$ & 11 & 09 & 20 & 0.287 \\
Total & & 40 & 20 & 60 & \\
\hline
\end{tabular}

Valores de $\mathrm{P} \leq(0,05)$ são significantes.

necessidades de meios de cultura seletivos, tempo prolongado de incubação e contaminação por bactérias indesejáveis, restringem os estudos epidemiológicos a poucos centros de pesquisas no Brasil. Neste trabalho, 70\% das amostras cultivadas em SP4 e 63,3\% em UB apresentaram contaminação. $\mathrm{O}$ alto percentual de culturas contaminadas evidencia a necessidade de aprimoramento dos meios de cultura e das técnicas de cultivo destinados ao isolamento de micoplasmas e ureaplasmas em ovinos. Todos os isolados obtidos de ureaplasmas foram de animais apresentando algum sinal clínico de problema reprodutivo, o que sugere a implicação desse microrganismo em processos patogênicos. Foram descritos o envolvimento dos molicutes nas enfermidades do trato genital de pequenos ruminantes em diferentes países (COTTEW et al., 1974; DOIG \& RUHNKE, 1977; BALL \& MCCAUGHEY, 1982; JONES et al., 1983; KAPOOR et al., 1984; LIVINGSTON JUNIOR \& GAUER, 1983; NICHOLAS et al., 1999; KIDANEMARIAM et al., 2005). A importância desses microrganismos na espécie bovina como causador de infecções que resultam em abortos e infertilidade, além de surtos da síndrome de vulvovaginite granular (VVG), comprovou envolvimento dos molicutes como patógenos do sistema reprodutivo (RUHNKE \& ROSENDAL, 1994; CARDOSO et al., 2000; LYSNYANSKY et al., 2009). Essas bactérias são consideradas oportunistas por excelência e a sua patogenicidade, na grande maioria das espécies, pode ser questionada, principalmente pela sua presença em hospedeiros sadios. Fatores predisponentes inerentes aos hospedeiros, ainda não conhecidos, e a presença dos molicutes podem estar associados à manifestação das enfermidades reprodutivas. Em um dos trabalhos de LIVINGSTON JUNIOR \& GAUER (1975) foi relatado que entre nove sorotipos de micoplasmas estudados, somente um demonstrou correlação entre seu isolamento e presença de alterações clínicas no trato genital de ovinos, concordando com vários autores (COTTEW et al., 1974; LIVINGSTON JUNIOR \& GAUER, 1983; KAPOOR et al., 1984; NICHOLAS et al., 1999). A resposta imune nas micoplasmoses em animais adultos tem sido indicativo de importante fator da persistência do microrganismo no trato genital e na ausência ou presença de patologias. Para o diagnóstico dos molicutes, o cultivo pode ser prejudicado pelo tipo de amostra clínica, método de colheita, transporte e tempo no processamento das amostras (RIZZO, 2006). Esses fatores limitantes para o isolamento de molicutes justificam a utilização de técnicas moleculares no diagnóstico de rebanhos animais, sendo a PCR de ampla aplicabilidade na Medicina Veterinária para detecção desses agentes em diferentes estágios da doença (RIZZO, 2006; RAZIN \& TULLY, 1983). A PCR classe Mollicutes é utilizada principalmente como triagem em rebanhos, não permitindo identificação de gêneros e espécies, pois amplifica a região conservada do $16 \mathrm{~S}$ rRNA presente nos gêneros Achopleplasma, Mycoplamsa, Ureaplasma e Spiroplasma. Neste trabalho, foram obtidas reações positivas na PCR classe Mollicutes em amostras provenientes de animais sadios e com vulvovaginite e no teste de correlação não houve associação entre as alterações reprodutivas e a presença desses microrganismos. Na Irlanda do Norte, houve diferenças na patogenicidade entre micoplasmas da mesma espécie, isolados de diferentes rebanhos, sendo algumas estirpes patogênicas e outras não (MCCAUGHEY et al., 1979; BALL \& MCCAUGHEY, 1982;). A PCR gênero Ureaplasma foi utilizada para avaliar a frequência desse gênero nos rebanhos ovinos e, como na PCR classe Mollicutes, não houve associação entre vulvovaginite e PCR positiva. Estes ureaplasmas de origem ovina e caprina não receberam ainda a designação de espécie, sendo apenas conhecidas suas características sorológicas, nas quais é fundamentada a classificação em nove sorotipos (HOWARD \& POCOCK, 1983), sendo o sorotipo IX associado à infertilidade (LIVINGSTON JUNIOR \& GAUER, 1978). Além disso, a PCR é amplamente utilizada na Medicina Veterinária como diagnóstico das doenças infecciosas, entretanto, sua interpretação deve 
ser criteriosa, pois detecta o material genético dos microrganismos, o que não permite afirmar a viabilidade destes. O diagnóstico definitivo deve ser realizado pela associação dos achados clínicos aos resultados laboratoriais, o que permite a preconização do tratamento adequado e consequente controle da doença no rebanho.

No Brasil, o diagnóstico restrito a poucos laboratórios e ausência de diagnósticos específicos para molicutes, causadores de problemas reprodutivos em ovinos, não permite avaliar a frequência desses agentes em nossos rebanhos. Essa dificuldade deve alertar a vigilância epidemiológica para estabelecer estratégias de controle mais aprimoradas sobre esses agentes infecciosos pouco estudados (DAMASSA et al., 1983; PUGH, 2005; RIZZO, 2006).

\section{CONCLUSÃO}

Foi confirmada a presença de Ureaplasma spp e Mycoplasma spp, por meio de isolamento, no rebanho ovino do Estado de São Paulo, Brasil. Das 60 amostras estudadas, obteve-se o isolamento de Ureaplasma spp em $31,8 \%$ em amostras não contaminadas, enquanto a detecção por PCR de Ureaplasma spp foi maior, ou seja, 66,7\%. A ocorrência de isolamento de Ureaplasma spp, somente em ovinos com problemas reprodutivos, sugere a associação desse microrganismo como patógeno do trato reprodutivo.

\section{COMITÊ DE ÉTICA E BIOSSEGURANÇA}

O projeto intitulado "Avaliação clínica e estudo da prevalência de fêmeas ovinas infectadas por micoplasmas na região de Piedade, SP - Avaliação da infecção sobre a produtividade do rebanho" foi aprovado pela comissão de bioética da Faculdade de Medicina Veterinária e Zootecnia da Universidade de São Paulo na data de 26 de setembro de 2005.

\section{REFERÊNCIAS}

ALMEIDA NETO, J.B. et al. Ocorrência de Mycoplasma conjunctivae em ovinos sadios e com ceratoconjuntivite infecciosa, no estado de Pernambuco. Arquivos do Instituto Biológico, São Paulo, v.71, n.1, p.79-81, 2004. Disponível em: <http://www.biologico.sp.gov.br/docs/arq/V71_1/almeida.pdf〉. Acesso em: 06 dez. 2010.

AZEVEDO, E.O. et al. Contagious agalactia by Mycoplasma agalactiae in small ruminants in Brazil: first report. Brazilian Journal of Microbiology, v.37, p.576-581, 2006. Disponível em: <http://www.scielo.br/ scielo.php?script=sci_arttext\&pid=S 1517 $83822006000400033 \& \operatorname{lng}=$ pt\&nrm=iso>. Acesso em: $06 \mathrm{dez}$. 2010. doi: $10.1590 / \mathrm{s} 1517-83822006000400033$.

BALL, H.J.; MCCAUGHEY, W.J. Experimental production of vulvitis in ewes with a ureaplasma isolate. Veterinary Record, v.110, n.19, p.581, 1982.
BALL, H.J. et al. Persistance of ureaplasma genital infection in naturally-infected ewes. British Veterinary Journal, v.140, n.4, p.347-353, 1984.

BERGEY'S. Manual of determinative bacteriology. Michigan: Michigan State Universty, 2001. Disponível em: <http://www.uiweb.uidaho.edu/micro_biology/250/ IDFlowcharts.pdf $>$. Acesso em: 19 jul. 2010.

BUZINHANI, M. et al. Detecção de Mycoplasma spp. e Ureaplasma diversum em vacas com distúrbios reprodutivos. Arquivo Brasileiro de Medicina Veterinária e Zootecnia, v.59, p.1368-1375, 2007. Disponível em: <http://www.scielo.br/ pdf/abmvz/v59n6/03.pdf >. Acesso em: de dez. 2010.

CARDOSO, M.V. et al. Ureaplasma diversum and reproductive disorder in Brazilian cows and heifers; first report. Animal Reproduction Science, v.66, p.137-143, 2000. Disponível em: <http:// www.sciencedirect.com/science?_ob=MImg\&_imagekey=B6T43416 BXF0-2-2\&_cdi $=4963 \&_{-}$_user $=5674931 \&$ _pii $=$ S $0378432000001767 \&$ \& origin=browse\&_zone $=\mathrm{rslt}_{-} 1 \mathrm{ist}$ item\&_coverDate $=11 \% 2 \mathrm{~F} 01 \% 2 \mathrm{~F} 20$ $00 \&$ \& k = $999369996 \& \mathrm{w} c \mathrm{~h} \mathrm{p}=\mathrm{d} \mathrm{G} \mathrm{L} \mathrm{z} \mathrm{V} \mathrm{l} \mathrm{b} \mathrm{-}$ zSkWA\&md5=7c400b100048e98907f373deb334bdbf\&ie $=/$ sdarticle.pdf>. Acesso em: 06 dez. 2010.

CLAYDE, W.A. Mycoplasma: animal host interrelationships. In: RAZIN, S.; TULLY, J.G. Methods in Mycoplasmology, Mycoplasma characterization. New York: AcadeVic, 1983. v.1, p.15-19.

COTTEW, G.S. et al. Isolation of a mycoplasma from vulvovaginitis in sheep. Australian Veterinary Journal, v.50, n.12, p.576-577, 1974.

DAMASSA, A.J. et al. Caprine mycoplasmosis: wide spread infection in goats with Mycoplasma mycoides subspecies mycoides (large colony type). American Journal of Veterinary Research, v.44, n.2, p.322-325, 1983.

DOIG, P.A.; RUHNKE, H.L. Isolation of ureaplasma from sheep with granular vulvitis. Veterinary Record, v.100, n.26, p.179-180, 1977.

DUSSURGET, O.; DUSSOIX, D.R. Rapid, sensitive PCR- based detection of Mycoplasmas in stimulated samples of animal soro. Applied and Environmental Microbiology, v.60, p.953-959, 1994.

FAN, H.H. et al. Application of polymerase chain reaction with arbitrary primers to strain identification of Mycoplasma gallisepticum. Avian Diseases, v.39, n.4, p.729-735, 1995.

GREGORY, L. et al. Surto de ceratoconjuntivite infecciosa dos caprinos causada por Mycoplasma conjunctivae em caprinos adultos, criados no Estado de São Paulo. Arquivos do Instituto Biológico de São Paulo, v.70, n.2, p.179-181, 2003. Disponível em: <http://www.biologico.sp.gov.br/docs/arq/V70_2/ gregory.pdf>. Acesso em: 06 dez. 2010.

GREGORY, L. et al. Primeiro isolamento de ureaplasma sp em sêmen e zaragatoa vaginal de ovinos no Estado de São Paulo. In: INTERNATIONAL CONGRESS ON ANIMAL REPRODUCTION, 15., 2004, Porto Seguro, BA. Anais... Porto Seguro: Colégio Brasileiro de Reprodução Animal, 2004. V.1, 312p. p.280. 
HOWARD, C.J.; POCOCK, D.H. Comparison of ureaplasmas from sheep and goats with Ureaplasma diversum and $\boldsymbol{U}$. urealyticum. Journal of General Microbiology, v.129, n.10, p.3197-202, 1983.

JONES, G.E. et al. Isolation of exotic mycoplasma from sheep in England. Veterinary Record, v.113, n.3, p.540, 1983.

KAPOOR, S.G. et al. Prevalence of mycoplasma/acholeplasma in the genital tract of sheep. Indian Journal Animal Sciences, v.54, n.7, p.553-556, 1984.

KIDANEMARIAM, A. et al. Ulcerative balanitis and vulvitis of Dorper sheep in South Africa: a study on its aetiology and clinical features. Journal of the South African Veterinary Association, v.76, n.4, p.197-203, 2005.

KUMAR et al. Granular vulvovaginitis (GVV) in sheep experiment ally induced with mycoplasma ovine/caprine serogroup 11. Acta Veterinaria Brno, v.61, p.241-249, 1992. Disponível em: 〈http://actavet.vfu.cz/pdf/199261040241.pdf〉. Acesso em: 06 dez. 2010. doi:10.2754/avb199261040241.

LAUERMAN, L.H. Mycoplasma PCR assays. In: LAUERMAN, L.H. (Ed.). Nucleic acid amplification assays for diagnosis of animal diseases. Turlock, CA: American Association of Veterinary Laboratory Diagnosticians, 1998. p.41-42.

LIVINGSTON JUNIOR, C.V.; GAUER, B.B. A specific ureaplasmal serotype associated with ovine uterine infections. American Journal Veterinary Research, v.39, n.10, p.1699-1701, 1978.

LIVINGSTON JUNIOR, C.V.; GAUER, B.B. Occurrence of Mycoplasma sp (2D) in Texas sheep flocks. American Journal Veterinary Research, v.44, n.5, p.868-869, 1983.

LYSNYANSKY, I. et al. Identification of Mycoplasma bovigenitalium and Mycoplasma canadense from outbreaks of granulopapular vulvovaginitis in dairy cattle in Israel. Veterinary Record, v.165, n.2, p.319-322, 2009. Disponível em: <http://veterinaryrecord.bmj.com/content/165/11/ 319.full.pdf>. Acesso em: 06 dez. 2010. doi:10.1136/ vr.165.11.319.

MCCAUGHEY, W.J. et al. Ureaplasma spp isolated from ewes in Northern Ireland. Veterinary Record, v.104, n.17, p.397398, 1979.

NICHOLAS, R.A.J. et al. Isolation of Mycoplasma ovine/ caprine serogroup 11 from infertile sheep in Britain. Veterinary Record, v.145, n.9, p.434-435, 1999. Disponível em: <http:/ /veterinaryrecord.bmj.com/content/145/15/434.full.pdf >. Acesso em 06 dez. 2010. doi:10.1136/vr.145.15.435.

PUGH, D.G. Clínica de ovinos e caprinos. In: MOBINI, S. et al. Teriogenologia de ovinos e caprinos. São Paulo: Roca, 2005. Cap.6, p.206.

RANA, J.S. et al. Pathology of genital tract of goats experimentally infected with Mycoplasma serogroup 11 . Indian Journal of Animal Sciences, v.63, n.7, p.706-709, 1993.

RAZIN, S. The genus Mycoplasma and related genera (Class Mollicutes). In: DWORKIN, M. et al. (Ed.). The prokaryotes. New York: Springer, 2006. p.836-904.

RAZIN, S. \& TULLY, J.G. Mycoplasma characterization. In: RAZIN, S.; TULLY, J.G. Methods in mycoplasmology. New York: Academics, 1983. V.1, p.504.

RIZZO, H. Avaliação clínica e estudo da ocorrência de fêmeas ovinas infectadas por micoplasmas na região de Piedade, SP. 2006. 111f. Dissertação (Mestrado em Clínica Médica) - Faculdade de Medicina Veterinária e Zootecnia, Universidade de São Paulo, SP.

RUHNKE, H.L.; ROSENDAL, S. Useful protocols for diagnosis of animal mycoplasmas. In: WHITFORD, H.W. et al. (Ed.). Mycoplasmosis in animals: laboratory diagnosis. Ames, Iowa: Iowa State University, 1994. p.141-144.

VAN KUPPEVELD, F.J.M. et al. Genus-and species-specific identification of mycoplasmas by $16 \mathrm{~S}$ RNA amplification. Applied and Environmental Microbiology, v.58, n.8, p.2606-2615, 1993. 